\title{
A single-center 10-year retrospective study of clinical features and surgical treatment of spinal metastasis from cholangiocarcinoma
}

\author{
Shuzhong Liu ${ }^{1 \#}$, Xi Zhou ${ }^{1 \#}$, Muchuan Wang ${ }^{1 \#}$, Siyuan Yao ${ }^{1}$, Tong Niu ${ }^{1}$, Chengao Gao ${ }^{1}$, Ziquan Li ${ }^{1}$, \\ Zhen Huo ${ }^{2}$, Yipeng Wang $^{1}$, Yong Liu ${ }^{1}$ \\ ${ }^{1}$ Department of Orthopaedic Surgery, Peking Union Medical College Hospital, Peking Union Medical College and Chinese Academy of Medical \\ Sciences, Beijing, China; ${ }^{2}$ Department of Pathology, Peking Union Medical College Hospital, Chinese Academy of Medical Science \& Peking Union \\ Medical College, Beijing, China \\ Contributions: (I) Conception and design: S Liu, X Zhou, Y Liu; (II) Administrative support: S Liu, X Zhou, Y Liu; (III) Provision of study materials \\ or patients: Y Liu; (IV) Collection and assembly of data: S Liu, X Zhou, M Wang, S Yao, T Niu, C Gao, Z Li, Z Huo; (V) Data analysis and \\ interpretation: S Liu, X Zhou, Y Wang, Y Liu; (VI) Manuscript writing: All authors; (VII) Final approval of manuscript: All authors. \\ "These authors contributed equally to this work. \\ Correspondence to: Yong Liu, MD. Department of Orthopaedic Surgery, Peking Union Medical College Hospital, Peking Union Medical College and \\ Chinese Academy of Medical Sciences, No. 1 Shuaifuyuan Wangfujing, Beijing 100730, China. Email: liuyong_pumch@163.com.
}

Background: This study intends to discuss the clinical features, therapeutic strategies, and patients' prognostic features and to share our expertise in handling this entity. Current research is one of Asia's extensive MSCCA clinical studies until now.

Methods: Four MSCCA patients who were operated in our hospital's bone tumor center from January 2010 to January 2020 were chosen. Our team reviewed a retrospective study of the medical history and records of surgery, imaging data, and pathology reports (both primary and metastatic spinal tumors) of all MSCCA patients. We applied two surgical therapies in this study, including open surgery and percutaneous vertebroplasty. A predetermined analysis of patients' original clinical data was performed, and regular followup was performed after the operation.

Results: Of the four patients, one was male and three were female. The age ranged from 60 to 70 years. The time duration between the diagnosis of cholangiocarcinoma (CCA) and the diagnosis of spinal metastases ranged from 0 to 11 months. Spinal metastatic disease was mainly located in the thoracic spine $(\mathrm{n}=4 ; 100 \%)$, followed by the cervical spine $(\mathrm{n}=1 ; 25.0 \%)$. Postoperatively, in the four patients, the symptoms improved and the VAS score was decreased. During the follow-up visit, the progression of the local spinal tumors at the site of primary spinal surgery was detected in three patients $(75.0 \%)$. Three patients died from the disease during the follow-up period, and one patient is still alive. The time ranged from 6 to 13 months for spinal surgery to the patient's death.

Conclusions: Taken together, the prognosis of patients with MSCCA is poor. Surgical treatment can dramatically improve patients' quality of life and helps to extend a patient's survival. In terms of surgical treatment, appropriate surgical treatment should be selected according to the general condition of the patient and the relevant characteristics of spinal metastases.

Keywords: Cholangiocarcinoma (CCA); spinal metastases; clinical features; surgical treatment; open surgery; percutaneous vertebroplasty; prognosis

Submitted Aug 09, 2020. Accepted for publication Nov 04, 2020.

doi: 10.21037/apm-20-1576

View this article at: http://dx.doi.org/10.21037/apm-20-1576 


\section{Introduction}

Cholangiocarcinoma (CCA) is a malignant tumor that affects various parts of the bile duct tree; it develops as a result of abnormal differentiation of the epithelial cells (1-3). In Western countries, the incidence rate of CCA is about $1-2 / 100,000$ individuals, while in Southeast Asia, the incidence rate is $0.1-71.3 / 100,000$ individuals per year (2). CCA progresses locally through the lymphatic system and metastasizes through the veins (1-3). Reports from the literature suggested that CCA is one of the rarest primary malignancies that metastasize to the spine, and the prevalence of spinal metastasis in patients with CCA is accounting for $4-15 \%(4,5)$. In a recent analysis of CCA and spinal metastases, Goodwin et al. found 16 CCA spinal metastasis patients, and most of them had multiple metastases at the time of diagnosis (6). The median survivability for primary and spinal metastases is very short (1.5 months after primary ACC diagnosis) (4-6). However, the treatment strategies and prognosis of patients with MSCCA remain unclear because of the relatively restricted number of patients with this condition and the lack of clinical attention.

To date, only a few reports of CCA spinal metastases have been published $(4,5)$. The present study presents a case series of four MSCCA patients who received spinal surgical intervention. A retrospective analysis of more than 1,000 cases of spinal metastatic tumors treated at our center in the past 10 years was conducted; of all these cases, only four patients were diagnosed with spinal metastases from CCA. We have introduced the largest series of MSCCA patients in Asia with a multidisciplinary treatment experience through the present paper. We present the following article in accordance with the STROBE reporting checklist (available at http://dx.doi.org/10.21037/apm-20-1576).

\section{Methods}

Current research consisted of four consecutive patients with MSCCA surgically treated in our department from January 2010 to January 2020. Pathological examination after spinal surgery supported the final diagnosis. All of these patient's clinical data and surgical history, imaging features, and pathological examination findings were evaluated. In May 2020, the final follow-up was accomplished. The study was conducted in accordance with the Declaration of Helsinki (as revised in 2013). The study was approved by Medical Ethics Committee of Peking Union Medical College Hospital (NO. S-K1268), and the informed consent for the surgical procedure of all participants was obtained.

Before spine surgery, all patients were assessed by computed tomography (CT), magnetic resonance imaging (MRI), and X-ray of the spine. Computed tomography, bone scan or positron emission tomography (PET), and chest and abdomen CT scans were executed to determine the metastases of the entire body. In all patients, the levels of different tumor markers in the peripheral blood were measured by chemiluminescence immunoassay. In accordance with the Frankel score and the American Spinal Injury Association (ASIA) impairment scale, preoperative neurological status was graded. The quality of life of all patients was measured in depth by the Karnofsky score, the Eastern Cooperative Oncology Group (ECOG) score, the visual analog scale (VAS) score system. The operations performed by personalized methods are all finished by our surgical team. To evaluate spinal integrity, the Spinal Instability Neoplastic Score (SINS) system was used and the updated Tokuhashi and Tomita scoring systems were employed to find out the patient's disease and to help in the progression of surgical procedures. For patients with good general health who could tolerate open surgery and were expected to survive for more than 3 months, complete tumor resection is recommended. Percutaneous vertebroplasty is also an option for patients with poor general condition, short life expectancy, or declining open surgery. The final implementation of all surgical procedures requires patient informed consent. In determining spinal stability, patients with a spinal instability score $>13$ are considered unstable. After surgery, patients were recommended to take radiotherapy and chemotherapy as adjuvant therapies. Local progression-free survival (PFS) and overall survival (OS) have been noted in detail after spinal surgery.

In our research, CT or MRI scans were replicated during follow-up visits after spinal surgery. Radiological evaluations (CT, MRI, or X-ray) of primary lesions and spinal metastases were executed regularly, 3 and 6 months after surgery. Outpatient visits and telephone interviews were used to obtain follow-up data. The patient's quality of life was reassessed according to the VAS score and the ECOG score 3 months after the surgery. The duration of time from the date of spinal surgery to death or the last follow-up is known as the follow-up period.

\section{Statistical analysis}

Progression-free survival was defined as the time interval 
Table 1 Clinical characteristics of 4 patients with metastatic cholangiocarcinoma of spine in our single centre

\begin{tabular}{|c|c|c|c|c|c|c|c|c|c|c|}
\hline Patients & $\begin{array}{l}\text { Age } \\
\text { (years), } \\
\text { sex }\end{array}$ & $\begin{array}{l}\text { Symptoms } \\
\text { and signs }\end{array}$ & $\begin{array}{c}\text { Spinal } \\
\text { metastases } \\
\text { location }\end{array}$ & $\begin{array}{c}\text { Incomplete } \\
\text { paralysis or } \\
\text { paralysis }\end{array}$ & $\begin{array}{l}\text { Resection } \\
\text { of primary } \\
\text { lesion }\end{array}$ & Surgery & $\begin{array}{l}\text { Adjuvant } \\
\text { treatment }\end{array}$ & $\begin{array}{c}\text { Postop } \\
\text { complications }\end{array}$ & $\begin{array}{l}\text { Progression- } \\
\text { free survival } \\
\text { (month) }\end{array}$ & $\begin{array}{l}\text { Overall } \\
\text { survival } \\
\text { (month) }\end{array}$ \\
\hline 2 & $\begin{array}{c}60 \\
\text { female }\end{array}$ & Back pain & $\begin{array}{l}\text { T8, multiple } \\
\text { lesions }\end{array}$ & No & Yes & $\begin{array}{l}\text { Percutaneous } \\
\text { vertebroplasty }\end{array}$ & $\begin{array}{l}\text { Neoadjuvant } \\
\text { chemotherapy }\end{array}$ & None & 9 & 13 \\
\hline 3 & $\begin{array}{c}64, \\
\text { female }\end{array}$ & Back pain & C6, T2 & No & Yes & $\begin{array}{c}\text { Posterior } \\
\text { decompression, } \\
\text { tumor resection, } \\
\text { bone cement } \\
\text { augmentation } \\
\text { as well as C4-T4 } \\
\text { internal fixation }\end{array}$ & Chemotherapy & None & 6 & 6 \\
\hline 4 & $\begin{array}{c}70 \\
\text { female }\end{array}$ & $\begin{array}{l}\text { Low back } \\
\text { pain }\end{array}$ & $\begin{array}{l}\text { T5, multiple } \\
\text { lesions }\end{array}$ & No & Yes & $\begin{array}{l}\text { Percutaneous } \\
\text { vertebroplasty }\end{array}$ & None & None & Alive & Alive \\
\hline
\end{tabular}

from the date of spinal surgery to local disease progression after surgery. Overall survival was the time interval from spinal surgery to the death of the patient or the end of January 2020. Statistical data were analyzed using SPSS 23.0. Counting data were described by proportion and frequency.

\section{Results}

\section{Clinical characteristics}

Of the four patients, one was male and three were female. In these patients, all patients were over 60 years old, with an age of 60 to 70 years. All four patients had a surgical history of primary CCA, three of whom had primary tumor resection with curative intent and one had an endoscopic biopsy. The interval between the diagnosis of CCA and the diagnosis of spinal metastases ranged from 0 to 11 months. During the preoperative examination, four patients had no metastases except for spinal regions. One patient received neoadjuvant chemotherapy, another patient received postoperative chemotherapy, and the remaining two patients refused to receive further adjuvant therapies.

Table 1 displays the clinical data of four patients with MSCCA. The most common clinical presentation was localized pain in the spine lasting 2-9 months. All patients experienced neurological symptoms including back pain or low back pain, but no severe spinal cord or nerve root compression occurred such as complete paralysis, incomplete paralysis, and dysfunction of stool. In four cases of the thoracic spine, lesions were primarily located (100\%) and one case of the cervical spine (25.0\%). In addition, four patients $(100 \%)$ had multiple spinal metastases. No patient had extraspinal metastases, including lung, liver, abdominal cavity, ribs, lymph nodes, peritoneum, or other soft tissue metastases.

Imaging results were similar to other spinal metastases characterized by osteolytic destruction. Osteolytic lesions can be seen on X-ray and CT scans. In this study, all patients with spinal metastases showed osteolytic lesions. Tumors can be surrounded by masses of paravertebral soft tissue. Two patients had spinal metastases with paravertebral expansion, and one patient had mild spinal cord compression (Figure 1). MRI examination usually showed iso-hypointensity on the T1-weighted image and iso-hyperintensity on the T2-weighted image (Figure 2). Enhanced MRI showed that the tumor was significantly enhanced, similar to the primary CCA. The detailed clinical characteristics of the spinal lesions in the four patients with MSCCA in this study are shown in Table 2.

The surgical treatment was carried out by our team, in which the doctors completed at least five years of professional training. Two of the patients underwent 

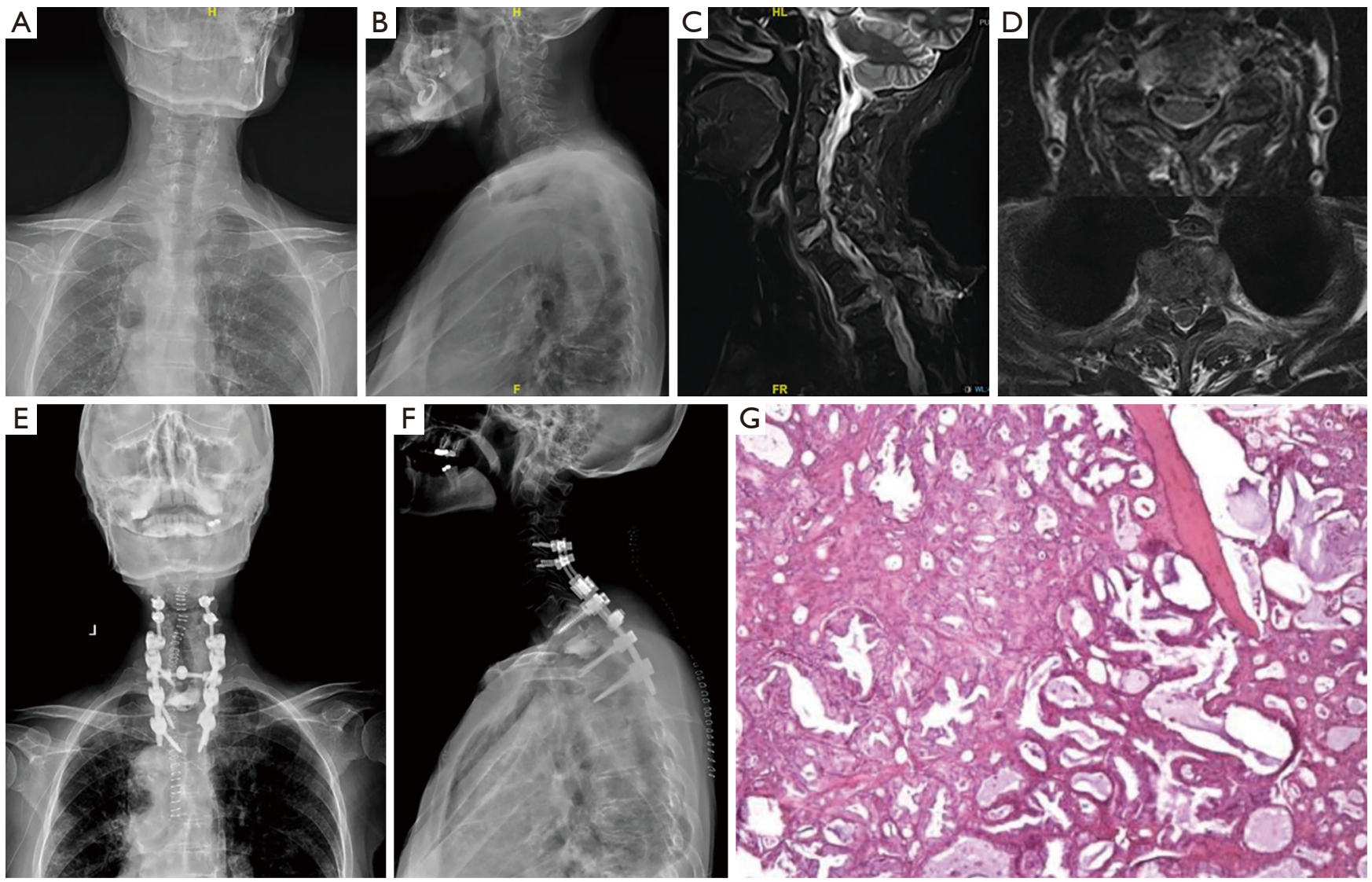

Figure 1 Radiographic and pathological images of a representative 64-year-old female patient (Case \#3). (A,B) Preoperative X-rays; (C,D) preoperative sagittal and transverse MRI revealing vertebral metastases of C6 and T2; (E,F) X-ray images of the cervicothoracic spine obtained postoperatively; $(\mathrm{G})$ microphotography showing characteristic nests of tumor cells $(\mathrm{H} \& \mathrm{E}, \times 100)$.

posterior spinal tumor resection, decompression of the spinal cord, and internal fixation, with an average blood loss of 1,600 (range: 1,200-2,000) $\mathrm{mL}$ at the time of surgery. Two other patients underwent percutaneous vertebroplasty to enhance spinal stability, with an average blood loss of $30 \mathrm{~mL}$ during the operations. Postoperative immunohistochemical results supported the final diagnosis of MSCCA. During the perioperative phase, no serious complications occurred, and routine follow-up was conducted after the surgery. After surgery, all four patients underwent treatment with a bisphosphonate.

\section{Follow-up}

In this retrospective study, local pain symptoms of all patients improved after surgical treatment. During the follow-up period, three patients $(75.0 \%)$ suffered from the local tumor progression and died of the disease, while one patient was still alive without any adjuvant treatment and had no disease progression at the last follow-up.

\section{Discussion}

CCA is aggressive cancer that is vulnerable to spinal metastasis and affects the biliary system (1-5). Owing to its aggressive and invasive characteristics, the prognosis of CCA is generally poor. Most CCA patients present with an unresectable primary lesion at diagnosis; hence, the median survival time is generally only $3-6$ months $(7,8)$. Therefore, in areas of high prevalence, CCA with spinal metastases should be considered as an important orthopedic health concern. This research is aiming to examine the clinical features and surgical treatment of MSCCA patients. In the 3 months following the investigation, Luvira et al. reported 163 newly diagnosed CCA cases, most of which were diagnosed by computed tomography (CT) or 

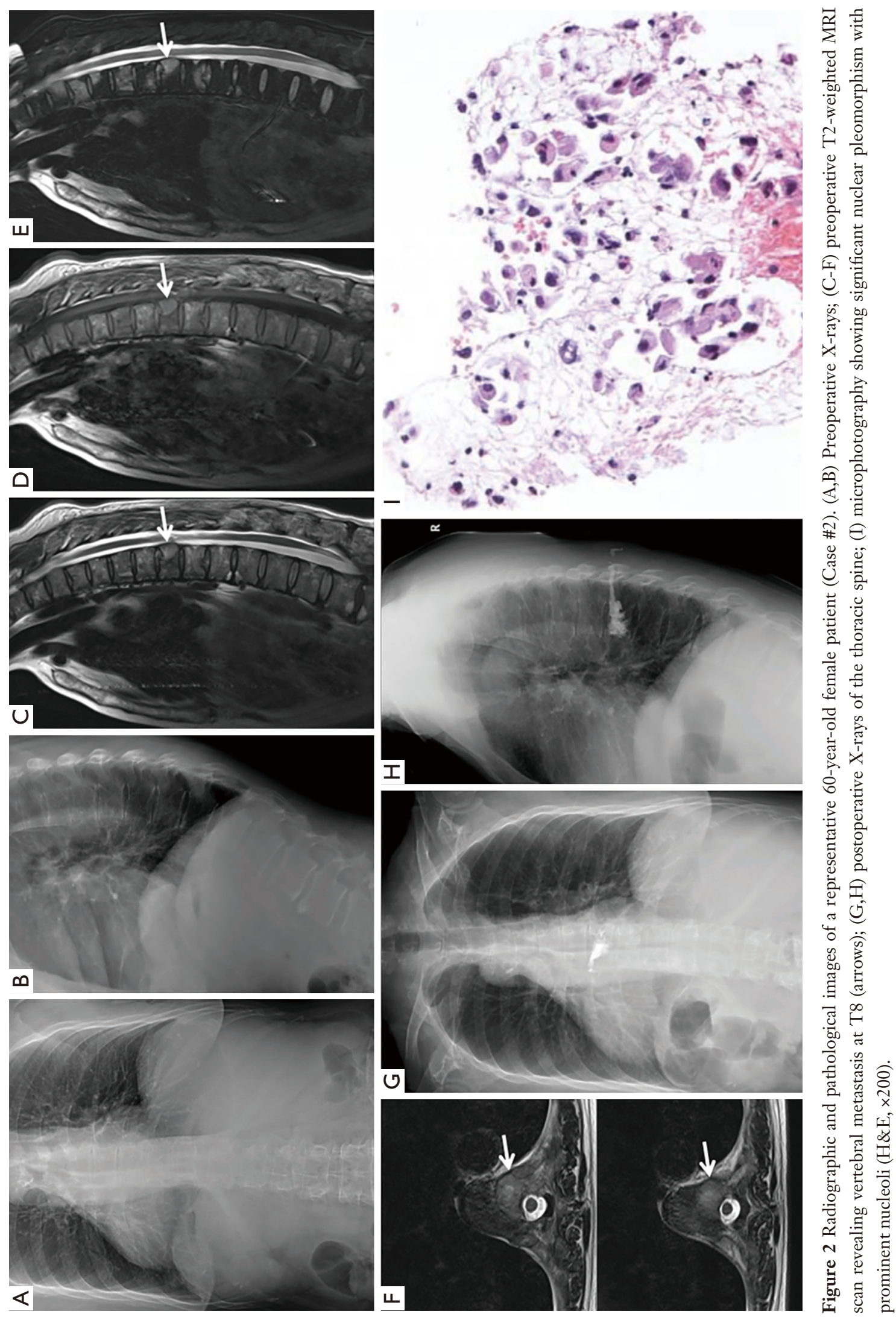
Table 2 Clinical data of spinal metastases in 4 patients with metastatic spinal cholangiocarcinoma in our single centre

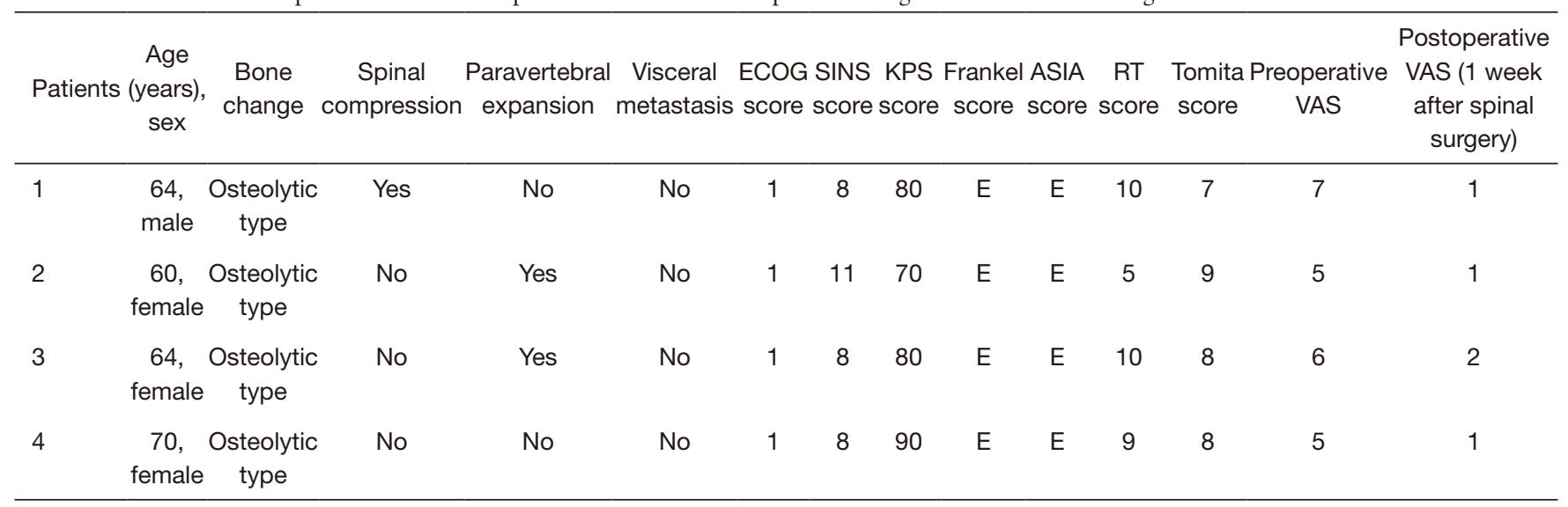

ECOG, Eastern Cooperative Oncology Group; SINS, Spinal Instability Neoplastic Score; KPS, Karnofsky; ASIA, American Spinal Injury Association; RT, Revised Tokuhashi.

magnetic resonance imaging (MRI)/magnetic resonance cholangiopancreatography (MRCP) (9). Their pathology report confirmed the incidence of spinal metastasis in only $8.6 \%$ of the cases (9). On the other hand, in a systematic analysis conducted by Goodwin et al., 16 patients with CCA and spinal metastases and a median survival of 1.5 months were reported (6). In Goodwin's study, only four patients had surgery along with adjuvant therapy $(21.1 \%)$, and another patient received surgical resection only (5.3\%) (6).

Lower back pain is a common clinical manifestation of MSCCA; nonetheless, it lacks specificity. Moreover, spinal metastases often involve hidden onset and are not easily distinguishable from other spinal disorders $(4,5,10,11)$. Our research demonstrated that, among the $>1,000$ cases of spinal metastases treated at our center within the last 10 years, only 4 patients were diagnosed with MSCCA. However, due to the previously stated reasons, the actual incidence could be higher. Therefore, CCA should be used as a differential diagnosis of spinal metastases.

Surgery is the simplest and most convenient radical treatment for CCA spinal metastasis with uncontrolled pain or neurological defects $(4,5,12-15)$. Because of the poor prognosis of patients with MSCCA, the main surgical interventions for this disease include open tumor resection and percutaneous vertebroplasty $(4,5,12-15)$. We found that CCA spinal metastases possess excessive blood flow, which is consistent with their imaging characteristics. MSCCA can be surrounded by masses of paravertebral soft tissue. Based on the experience of our single center, for patients with good general health who can tolerate surgery and are expected to survive for $>3$ months, open tumor resection is recommended. Percutaneous vertebroplasty (PVP) is another suitable option for patients with the poor general condition, short expected survival time, or declining open surgery. In addition, because MSCCA often presents osteolytic changes, posterior open surgery is more appropriate when the posterior wall of the vertebral body is damaged. In this case, PVP may cause bone cement leakage into the spinal canal, resulting in spinal cord compression. No matter what kind of operation method is adopted, the fundamental principle is to remove the spinal metastases as completely as possible under the condition that the circumstances permit. In addition, for MSCCA, how to ensure the stability of the spine and reduce the recurrence or progression rate is also a great challenge for spine surgeons. According to past reports, resectable primary CCA, single-segment spinal metastasis, Frankel score $>\mathrm{C}$, and moderate KPS score are the favorable prognostic factors for MSCCA (4,5,12-15). Thus, CCA resection combined with spinal surgery is a reasonable choice, because of the probability of these patients carrying other favorable tumor-specific factors that may affect the surgical decisionmaking $(4,5)$. Therefore, researchers recommend that if CCA patients with spinal metastases are encountered, those with (I) resectable primary site, (II) single-segment spinal metastases, (III) Frankel score of $\geq \mathrm{C}$, and (IV) moderate-tohigh Kanofsky score should undergo radical CCA resection combined with palliative spinal surgery, chemotherapy, and/or radiation therapy to improve the survival chances (4,5,12-15). Spinal surgery in MSCCA patients aims to reverse the neurological deficits, reduce pain, and improve the ambulatory status, but it may not improve the survival 
chances. Further research is warranted to assess the efficacy of surgical treatment in MSCCA.

Palliative treatment of MSCCA includes targeted therapy, bisphosphonate therapy, radiotherapy, and chemotherapy (16-20). When compared with hormonerefractory prostate cancer (5 months), kidney cancer (11.3 months), lung cancer (11.3 months), thyroid cancer (15.4 months), breast cancer (21.7 months), hormonetreated prostate cancer (58.3 months), and other metastatic tumors including hepatocellular carcinoma (8.7 months), the overall survival of MSCCA patients is much shorter (3 months only) (21-27). The main cause of poor survival, in this case, is that several patients with CCA remain asymptomatic until the disease progresses and are diagnosed only at stage III or IV, at which point of time, the tumor cannot be surgically removed. In addition, adjuvant therapy for CCA is considered to be poorly sensitive. Chemotherapy has been shown to slightly extend the survival time, and more research on stereotactic radiotherapy and targeted therapy are urgently needed to assess their potential (17-19). Past researches have shown that the survival period can be longer for chemotherapy and radiation therapy than for CCA resection alone (17-19). For most patients with spinal metastasis, bisphosphonate is the preferred treatment (20). The medication is favored in lowering the likelihood of fractures in the spine, pelvis, and parts of the skeleton other than the spine in addition to relieving pain to some degree.

Owing to the limited number of cases published, the exact effect of bisphosphonate therapy on patients with MSCCA remains unclear; nonetheless, it can still be routinely recommended.

The limitations of this study include that (I) the sample size of the study is small, and it is of retrospective nature. As a result, some data may have been lost, limiting the universality and accuracy of the results; (II) the primary CCA lesions were not surgically removed in all the patients, and only one patient was diagnosed by performing a biopsy of the primary lesion; (III) the study was conducted in a single center over a span of 10 years, and the adjuvant treatment methods had partially improved over this period of time; (IV) owing to the limited number of cases published, the prognostic factors could not be further analyzed, warranting cohort studies. Although this study has certain limitations, it demonstrates the clinical characteristics and surgical treatment analysis of patients with MSCCA. The present study's findings are expected to help enhance the patient's quality of life and also for the development of superior treatment models and prognostic assessment methods. This work also provides an estimation of the severity, natural history, survival rate, and prognostic factors of the disease, which can aid in augmenting the clinical management of MSCCA.

\section{Conclusions}

CCA is a highly invasive and clinically rare malignant tumor of the bile duct epithelium, which originates from the biliary system. The median survival time of patients with MSCCA is extremely short; however, the clinical importance of this entity needs to be further clarified.

In conclusion, patients with bile duct cancer and spinal metastases have a poor prognosis. For these patients, the overall survivability is not more than 12 months. Therefore, Palliative treatment is primarily prescribed to monitor the symptoms. Tumor resection, decompression, or percutaneous vertebroplasty can be contemplated for patients with neurological deficits or uncontrolled severe pain. For those in whom the expected survival period is comparatively longer, palliative surgery can be considered as a reasonable treatment choice.

\section{Acknowledgments}

We would like to thank our colleagues at the Departments of General surgery, Anesthesiology, Pathology, Nuclear medicine, Radiology, and Orthopaedic surgery for their support.

Funding: This study was supported by Peking Union Medical College Graduate Student Innovation Fund (2018) (Project No. 2018-1002-02-08; Grant recipient: S.L.). The funder had no role in study design, data collection and analysis, decision to publish, or preparation of the manuscript.

\section{Footnote}

Reporting Checklist: The authors have completed the STROBE reporting checklist. Available at http://dx.doi. org/10.21037/apm-20-1576

Data Sharing Statement: Available at http://dx.doi. org/10.21037/apm-20-1576

Conflicts of Interest: All authors have completed the ICMJE uniform disclosure form (available at http://dx.doi. 
org/10.21037/apm-20-1576). The authors have no conflicts of interest to declare.

Ethical Statement: The authors are accountable for all aspects of the work in ensuring that questions related to the accuracy or integrity of any part of the work are appropriately investigated and resolved. The study was conducted in accordance with the Declaration of Helsinki (as revised in 2013). The study was approved by Medical Ethics Committee of Peking Union Medical College Hospital (NO. S-K1268). The informed consent for the surgical procedure of all participants was obtained.

Open Access Statement: This is an Open Access article distributed in accordance with the Creative Commons Attribution-NonCommercial-NoDerivs 4.0 International License (CC BY-NC-ND 4.0), which permits the noncommercial replication and distribution of the article with the strict proviso that no changes or edits are made and the original work is properly cited (including links to both the formal publication through the relevant DOI and the license). See: https://creativecommons.org/licenses/by-nc-nd/4.0/.

\section{References}

1. Razumilava N, Gores GJ. Cholangiocarcinoma. Lancet 2014;383:2168-79.

2. Thammaroj P, Chimcherd A, Chowchuen P, et al. Imaging features of bone metastases from cholangiocarcinoma. Eur J Radiol 2020;129:109118.

3. Shin HR, Oh JK, Masuyer E, et al. Epidemiology of cholangiocarcinoma: an update focusing on risk factors. Cancer Sci 2010;101:579-585.

4. Sangsin A, Saiudom D, Pongmanee S, et al. Natural History and Prognostic Factors of Cholangiocarcinoma With Spinal Metastasis: A 10-Year Single Center Study. Clin Spine Surg 2018;31:E160-5.

5. Dowsiriroj P, Paholpak P, Sirichativapee W, et al. Cholangiocarcinoma with spinal metastasis: single center survival analysis. J Clin Neurosci 2017;38:43-48.

6. Goodwin CR, Abu-Bonsrah N, Boone C, et al. Nonhepatocellular carcinoma spinal metastases. J Clin Neurosci 2016;27:22-27.

7. Valle JW. Advances in the treatment of metastatic or unresectable biliary tract cancer. Ann Oncol 2010;21:vii345-8.

8. Zhang GW, Lin JH, Qian JP, et al. Identification of risk and prognostic factors for patients with clonorchiasis- associated intrahepatic cholangiocarcinoma. Ann Surg Oncol 2014;21:3628-37.

9. Luvira V, Nilprapha K, Bhudhisawasdi V, et al. Cholangiocarcinoma patient outcome in northeastern Thailand: single-center prospective study. Asian Pac J Cancer Prev 2016;17:401-6.

10. Paholpak P, Sirichativapee W, Wisanuyotin T, et al. Prevalence of known and unknown primary tumor sites in spinal metastasis patients. Open Orthop J 2012;6:440-4.

11. Kidambi T, Mahajan A, DiBardino D. Cholangiocarcinoma presenting as metastases to the cervical spine. Am J Med 2011;124:e1-2.

12. Rizvi S, Gores GJ. Pathogenesis, diagnosis, and management of cholangiocarcinoma. Gastroenterology 2013;145:1215-29.

13. Phanphaisarn A, Patumanond J, Settakorn J, et al. Prevalence and survival patterns of patients with bone metastasis from common cancers in Thailand. Asian Pac J Cancer Prev 2016;17:4335-40.

14. Bridgewater J, Galle PR, Khan SA, et al. Guidelines for the diagnosis and management of intrahepatic cholangiocarcinoma. J Hepatol 2014;60:1268-89.

15. Yusoff AR, Razak MM, Yoong BK, et al. Survival analysis of cholangiocarcinoma: a 10-year experience in Malaysia. World J Gastroenterol 2012;18:458-65.

16. Rose PS, Buchowski JM. Metastatic disease in the thoracic and lumbar spine: evaluation and management. J Am Acad Orthop Surg 2011;19:37-48.

17. Ortiz Gómez JA. The incidence of vertebral body metastases. Int Orthop 1995;19:309-11.

18. Sripa B, Pairojkul C. Cholangiocarcinoma: lessons from Thailand. Curr Opin Gastroenterol 2008;24:349-56.

19. Park J, Kim MH, Kim KP, et al. Natural history and prognostic factors of advanced cholangiocarcinoma without surgery, chemotherapy, or radiotherapy: a largescale observational study. Gut Liver 2009;3:298-305.

20. Thunyaharn N, Promthet S, Wiangnon S, et al. Survival of cholangiocarcinoma patients in northeastern Thailand after supportive treatment. Asian Pac J Cancer Prev 2013;14:7029-32.

21. Dohzono S, Sasaoka R, Takamatsu K, et al. Overall survival and prognostic factors in patients with spinal metastases from lung cancer treated with and without epidermal growth factor receptor tyrosine kinase inhibitors. Int $\mathrm{J}$ Clin Oncol 2017;22:698-705.

22. Sciubba DM, Goodwin CR, Yurter A, et al. A systematic review of clinical outcomes and prognostic factors for patients undergoing surgery for spinal metastases 
secondary to breast cancer. Global Spine J 2016;6:482-496.

23. Tatsui CE, Suki D, Rao G, et al. Factors affecting survival in 267 consecutive patients undergoing surgery for spinal metastasis from renal cell carcinoma. J Neurosurg Spine 2014;20:108-16.

24. Crnalic S, Lofvenberg R, Bergh A, et al. Predicting survival for surgery of metastatic spinal cord compression in prostate cancer: a new score. Spine (Phila Pa 1976) 2012;37:2168-2176.

25. Sellin JN, Suki D, Harsh V, et al. Factors affecting

Cite this article as: Liu S, Zhou X, Wang M, Yao S, Niu T, Gao C, Li Z, Huo Z, Wang Y, Liu Y. A single-center 10-year retrospective study of clinical features and surgical treatment of spinal metastasis from cholangiocarcinoma. Ann Palliat Med 2021;10(2):1825-1833. doi: 10.21037/apm-20-1576 survival in 43 consecutive patients after surgery for spinal metastases from thyroid carcinoma. J Neurosurg Spine 2015;23:419-28.

26. Lee MH, Lee SH, Kim ES, et al. Survival-related factors of spinal metastasis with hepatocellular carcinoma in current surgical treatment modalities: a single institute experience. J Korean Neurosurg Soc 2015;58:448-53.

27. Doherty B, Nambudiri VE, Palmer WC. Update on the diagnosis and treatment of cholangiocarcinoma. Curr Gastroenterol Rep 2017;19:2. 